\title{
Immunocytochemistry in the identification of vascular invasion in breast cancer
}

\author{
R BETTELHEIM,${ }^{*}$ D MITCHELL,$\dagger$ BA GUSTERSON $\ddagger$ \\ From the *South West Thames Regional Cancer Organisation, the †Department of Histopathology, Royal \\ Marsden Hospital, and the $\ddagger$ Ludwig Institute for Cancer Research, Haddow Laboratories, Sutton, Surrey
}

SUMMARY Immunocytochemical stains were used to find out whether they would increase the accuracy of detecting lymphatic and vascular invasion by primary breast cancer cells over conventional histological methods. Immune probes for type IV collagen were of value in confirming the conventional diagnosis of vascular invasion while stains for factor VIII assisted in differentiating small blood vessels from lymphatic channels. Antibodies to type IV collagen also increased the accuracy and rate of detection achieved by conventional histology.

The presence of tumour emboli in vascular channels within the framework of primary breast cancers is considered to carry a bad prognosis. ${ }^{1-3}$ To ascertain whether a more accurate diagnosis and increased incidence of vascular invasion within primary breast tumours could be achieved, we used selected immunocytochemical methods in conjunction with haematoxylin and eosin stains and Weigert's resorcin-fuchsin elastin stain. In addition, we hoped to be able to differentiate lymphatic channels from small blood vessels more reliably, a differentiation of possible importance in assessing the distribution of further metastatic spread.

\section{Material and methods}

Portions of 30 unselected invasive breast carcinomas with generous stromal edges were fixed in methacarn, processed by routine methods, and embedded in paraffin. ${ }^{4}$ Serial sections were cut at 3 $\mu \mathrm{m}$ and stained by haematoxylin and eosin, Weigert's resorcin-fuchsin, and by immunocytochemical methods for type IV collagen and factor VIII. These methods enabled us to examine the same structures in all the sections and compare their characteristics as depicted by each of the stains. The immunocytochemical staining was carried out by an indirect procedure using an alkaline phosphatase conjugated second antibody. ${ }^{4 \mathrm{~S}}$ The specificities of the antibodies to type IV collagen and factor VIII have been described previously. ${ }^{6-9}$

Accepted for publication 7 December 1983

\section{Results}

Antibodies to type IV collagen delineated the basement membranes surrounding both lymphatic and vascular channels (Fig. 1a, b). Breast carcinomas rarely show demonstrable basement membranes. ${ }^{4}$ Antibodies to factor VIII stained the endothelium of blood vessels but not that of lymphatics (Fig. 1c). Endothelial staining was strongest in capillaries; veins were more prominent in their expression of factor VIII than arteries but the intensity of staining declined with increasing vessel diameter.

By means of haematoxylin and eosin preparations the breast tumours were all classified as infiltrating duct carcinomas. Eleven of the $\mathbf{3 0}$ lesions showed clumps of malignant cells within endothelial lined spaces, regarded in six cases as lymphatic and in five as both lymphatic and vascular. Twelve tumours were negative for vascular and lymphatic invasion (Table). In seven cases it was doubtful whether there was true vascular invasion.

By means of the anti-basement membrane type IV collagen antibodies, the 11 positive and 12 negative cases of invasion diagnosed by haematoxylin and eosin were confirmed. Of the inconclusive group, four cases consisted of tumour emboli in endothelial lined structures surrounded by basement membranes, while the remaining three were due to tumour cells present in stromal spaces created by shrinkage artefact.

Factor VIII stains further confirmed the 12 cases as negative for vascular invasion. In the original group of 11 tumours positive for vascular invasion, some of the structures described on haematoxylin 


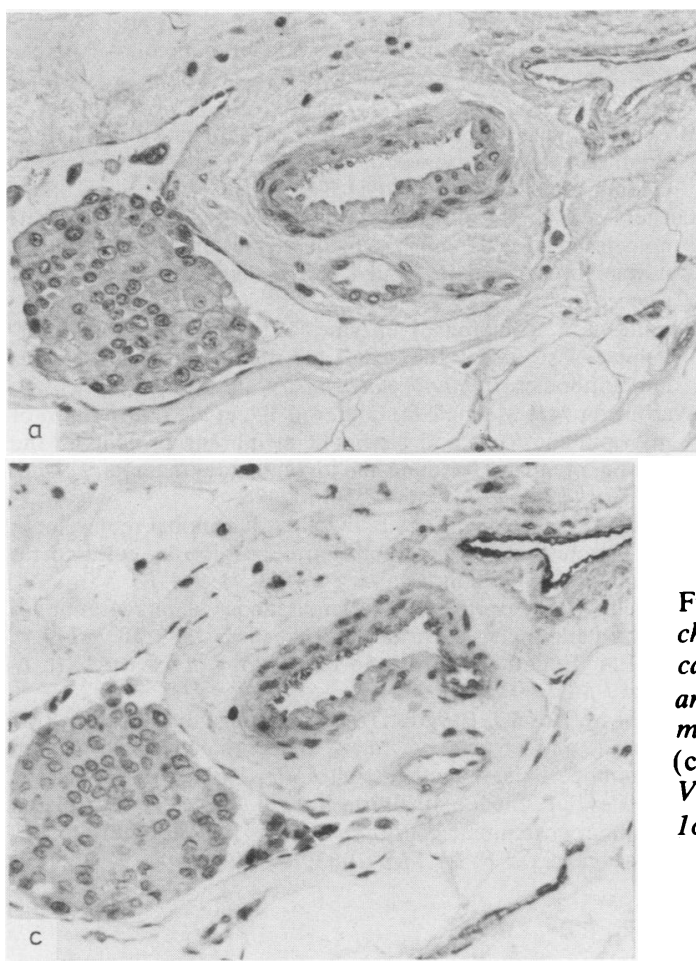

and eosin as lymphatics were recognised as small blood vessels in three more cases, increasing the incidence of both lymphatic and blood vessel involvement from five to eight cases. Factor VIII stains also confirmed the type IV collagen interpretation of the seven doubtful cases: three remained negative, and of the four positive preparations two showed tumour cells in both lymphatics and blood vessels. Two showed invasion of the lymphatic channels only, bringing the total number of positive cases to five for lymphatics and 10 for both types of vessels.

Weigert's resorcin-fuchsin stain was unhelpful in 18 cases and in 12 cases confirmed information provided by haematoxylin and eosin staining.

Table Incidence of vascular invasion

\begin{tabular}{llll}
\hline $\begin{array}{l}\text { Vascular } \\
\text { invasion }\end{array}$ & $\begin{array}{l}\text { Conventional } \\
\text { haematoxylin and } \\
\text { eosin preparation }\end{array}$ & \multicolumn{2}{l}{ Immunocytochemistry } \\
\cline { 3 - 4 } & Type IV & Factor VIII \\
\hline Present & 11 & 15 & 15 \\
& $(6 \mathrm{~L}, 5 \mathrm{~B}+\mathrm{L})$ & 15 & $(5 \mathrm{~L}, 10 \mathrm{~B}+\mathrm{L})$ \\
Absent & 12 & 15 & 0 \\
Inconclusive & 7 & 30 & 30 \\
Total & 30 & & \\
\hline B = blood vessels. & & \\
L = lymphatics. &
\end{tabular}

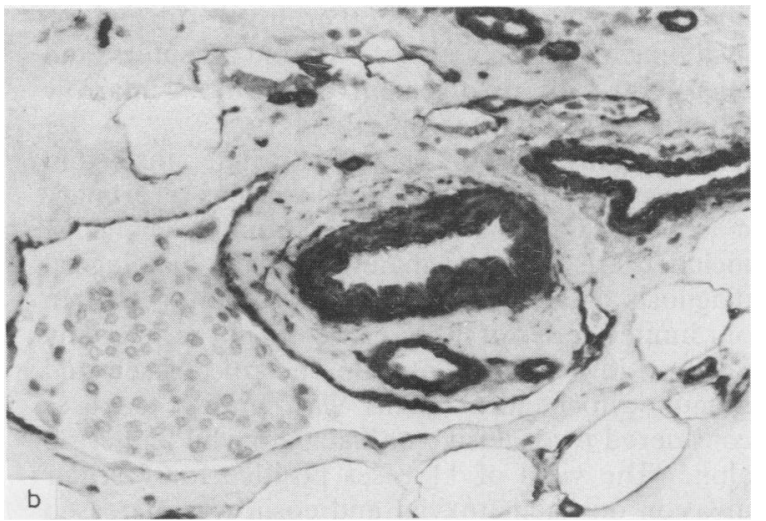

Fig. 1 (a) Vessels (two veins, two arteries, and a lymphatic channel containing a clump of tumour cells and several capillaries) in fibrofatty breast tissue stained by haematoxylin and eosin. (b) The same group of vessels with the basement membrane outlined using anti-type IV collagen antibodies.

(c) The same group of vessels stained with antibodies to factor VIII. Note the number of capillaries shown in Fig. 1 b and lc compared with Fig. 1a. Original magnification $\times 110$.

\section{Discussion}

This short histological survey has confirmed the pathological value of an immunocytochemical approach to the detection of vascular and lymphatic invasion within the substance of breast carcinomas.

The antibodies to type IV collagen delineated the basement membrane of the vascular and lymphatic channels. This made the positive identification of tumour emboli easier. Examples classed as negative for invasion did not, however, yield a positive result when the immunocytochemical as opposed to conventional morphological approach was used. Antibodies to type IV collagen also helped to distinguish between true tissue structures and spaces created by shrinkage artefact in the fibrous stroma, often "lined" by fibroblasi nuclei and therefore mimicking endothelium lined spaces on haematoxylin and eosin preparations. The observation of differential staining patterns by anti-factor VIII between blood vessels and lymphatics confirms previous findings by other workers. ${ }^{10}$

This preliminary study is now being extended to a larger series of cases and patients are being closely followed up to ascertain whether intratumoral invasion of lymphatics or capillaries has real prognostic importance. In addition, the occurrence of vascular 
invasion is being related to other prognostic indices, including axillary nodal state, steroid receptors, and micrometastatic involvement of the bone marrow (Redding, unpublished observation)."

This study allows us to conclude that thin haematoxylin and eosin stained sections of primary mammary carcinomas with a generous stromal edge included are adequate material for the histological diagnosis of vascular invasion by tumour cells. In our limited series of 30 cases we did not register any false positive interpretations. The role of selected immunocytochemical stains was limited to cases considered inconclusive on haematoxylin and eosin alone. The yield of 11 cases positive for vascular invasion on haematoxylin and eosin was increased by immunocytochemistry to a total of 15 of the 30 .

Immunocytochemical stain for factor VIII was valuable in identifying whether the tumour cells were in capillaries or lymphatics but did not increase the detection of invasion.

We thank Mr JC Gazet, consultant surgeon of the Royal Marsden Hospital, Mr JC Bull and Mr J Neely, consultant surgeons of Crawley Hospital, and Mr R Lloyd, of the Department of Histopathology, Crawley Hospital, for their valuable assistance.

\section{References}

' Bettelheim R, Neville AM. Lymphatic and vascular channel involvement within infiltrative breast carcinomas as a guide to prognosis at the time of primary treatment. Lancet 1981;ii:631.
${ }^{2}$ Nime FA, Rosen PP, Thaler HT, Ashikari R, Urban JA. Prognostic significance of tumour emboli in intramammary lymphatics in patients with mammary carcinoma. Am J Surg Pathol 1977;1:25-30.

${ }^{3}$ Rosen PP, Naigo PE, Braun DW Jr, Weathers E, DePalo A. Predictors of recurrence in Stage $1\left(T_{1} N_{0} M_{0}\right)$ breast carcinoma. Ann Surg 1981;109:15-25.

4 Gusterson BA, Warburton J, Mitchell D, et al. Distribution of myoepithelial cells and basement membrane proteins in the normal breast and in benign and malignant breast disease. Cancer Res 1982;42:4763-70.

${ }^{5}$ Avrameas S. Coupling of enzymes to proteins with gluteraldehyde. Use of the conjugates for the detection of antigens and antibodies. Immunocytochemistry 1969;6:40-52.

- Warburton MJ, Mitchell D, Ormerod EJ, et al. Distribution of myoepithelial cells and basement membrane proteins in the resting, pregnant, lactating and involuting rat mammary gland. $J$ Histochem Cytochem 1982;30:667-76.

' Liotta LA, Wicha MS, Foidart JM, et al. Hormonal requirement for basement membrane collagen deposition by cultured rat mammary epithelium. Lab Invest 1979;41:511-8.

${ }^{8}$ Mitchell DP, Gusterson BA. Simultaneous demonstration of keratin and mucin. J Histochem Cytochem 1982;30:707-9.

${ }^{9}$ Jaffe EA. Endothelial cells and the biology of Factor VIII. $N$ Engl J Med 1977;296:377-83.

${ }^{10}$ Kiyoshi M, Rosai J, Burgdorf WHC. Localization of factor VIII related antigens in vascular endothelial cells using an immunoperoxidase method. Am J Surg Pathol 1980;4:273-6.

" Dearnaley DP, Sloane JP, Imrie S, et al. Detection of isolated mammary carcinoma cells in marrow of patients with primary breast cancer. J R Soc Med 1983;76:359-64.

Requests for reprints to: Dr R Bettelheim, The Royal Marsden Hospital, The Haddow Laboratories, Clifton Avenue, Sutton, Surrey SM2 5PX, England. 